degradation of an image by the media of the eye, we have made densitometric measurements of a fluorescein-filled vessel in the posterior pole of the eye. Between days 25 and 32, there was a $43 \%$ decrease in the spread of the image of the vessel in the absence of any change in the refractive power or the axial length of the eye. These observations demonstrate that the optical quality of the kitten's eye is improving over this period and must play a significant part in determining the acuity of kittens.
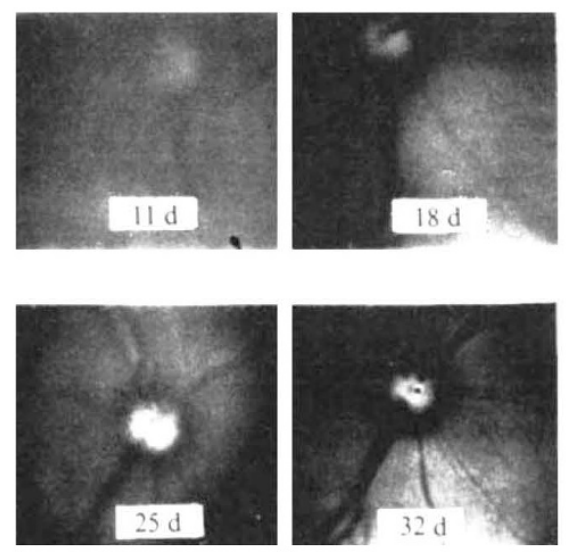

Fig. 1

Further, there is another important factor about the kitten's eye which must be considered by the visual physiologist. We have determined, by retinoscopy, the refractive error of eight eyes from seven kittens. During the first eight weeks of life, with the accommodation paralysed by atropine, the mean refractive error is $7.62 \mathrm{D}$ (range+15.00 D-+4.00 D). It should be noted that these are refractive error determinations for an object at infinity, and any object placed closer will require the kitten to use its accommodative power, which may be limited by the anterior displacement of the lens and its envelopment by the tunica vasculosa lentis. Thus, for example, if the kitten with a $7.50 \mathrm{D}$ hyperopia were placed in the middle of a $50-\mathrm{cm}$ diameter striped cylinder, it would be required to employ 11.5 D of accommodation to bring the stripes into focus. For the reasons cited above, we do not believe the kitten possesses anywhere near this accommodative power. It is indeed surprising that, in spite of these optical defects, it is possible to alter the development of receptive field properties of cortical cells ${ }^{2}$, although these results have not been confirmed (M. P. Stryker and H. Sherk, unpublished). For an out-of-focus optical system with a vertical slit pupil, vertical objects will be in better focus than horizontal objects. If the kitten's visual system responds as does the human astigmatic eye $^{3}$, the question arises, why are there not more vertically tuned cortical cells in normally

reared cats?

JOHN T. FLYNN

Duco I. Hamasaki

THOMAS E. FLYNN

MICHAEL BARRICKS

Bascom Palmer Eye Institute,

Department of Ophthalmology,

University of Miami School of Medicine, Miami, Florida 33152

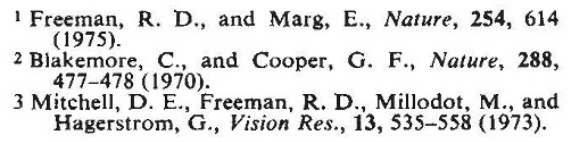

FreEMAN AND MARG REPLY-Accommodation and refractive error has nothing to do with our study as has been suggested ${ }^{1}$. The kittens were under general anaesthesia and the eye and its protective contact lens were optically corrected for the $57-\mathrm{cm}$ screen distance.

Optics has a great deal to do with the development of kittens and the determination of their sensitive or critical period of development. It is by means of slits, bars, and edges that the concepts of visual development and deprivation have been uncovered. The original work of Hubel and Wiesel ${ }^{2}$ demonstrated orientation of cortical receptive fields in the kitten as young as $8 \mathrm{~d}$, and others have done similar experiments. The optics of these eyes must be transmitting those forms.

There is no question that the optics of the kitten's eye improves up to about the fifth week, but this does not mean that it is the limiting factor in acuity. With good illumination (rather than a fluorescent source) retinal vessels of about $0.5^{\circ}$ width can be resolved at 3 weeks of age. It is likely that the optics are transmitting to the retina gratings of similar detail.

While we await the results of systematic optical modulation transfer function data from the kitten, we stand by our original statement:

"It is clear that the optical quality of the eye of the very young kitten is inferior to that of the adult. But on the basis of ophthalmoscopic observation we feel that it is unlikely that optical factors limit the acuity determined for the younger animals."

University of California,

School of Optometry,

Berkeley, California 94720

1 Flynn, J. T., Hamasaki, D. 1., Flynn, T. E., and Barricks, M., Nature, 257, 337-338 (1975).

2 Hubel, D. H., and Wiesel, T. N., J. Neurophysiol., 26, 994-1002 (1963).

\section{Basalt from DSDP holes}

Although Hammond et al. ${ }^{1}$ are concerned mainly with palaeolatitudes of the Ontong Java Plateau, where DSDP 289 was drilled, they give considerable attention to the basalt at the bottom of the hole. At long last it is good to see another radiometric age for basalt, no matter how flawed the age may seem to the authors. The latter "assign" an age of $109 \mathrm{Myr}$ to the basalt on the assumption that it must be older than sediments above it which are dated as $108 \mathrm{Myr}$ on biostratigraphic grounds. They find that the radiometric age of $80 \mathrm{Myr}$ which they actually obtain is in "error", and they cite a similar error in a radiometric analysis performed by Cox and Dalrymple ${ }^{2}$ to conclude that the "estimated analytical standard deviation arises almost entirely from uncertainties in the potassium measurements".

I can only suggest that uncertainties cut both ways. If a basalt dated at $80 \mathrm{Myr}$ is to be corrected to $109 \mathrm{Myr}$ it could just as well be corrected in the opposing direction to $51 \mathrm{Myr}$. In the latter case the basalt would be a sill. Needless to say the basalt would also be a sill if the authors were willing to accept their own date. As to their citation of Dalrymple and Cox I myself would cite MacDougall ${ }^{3}$. He found a basalt below Campanian strata in DSDP 10, western Atlantic, that gave a radiometric age of $16 \mathrm{Myr}$. The result was acceptable to MacDougall, from which one concludes that the basalt of DSDP 10 is a Miocene sill intruded into Campanian strata.

Those are the facts; however, impressions may not be out of place. The authors give me the impression that they are "bound and determined" to have the basalt as the oldest material in DSDP Hole 289. Why? Almost certainly because they assume that the basalt is basement. That is a common assumption in modern tectonophysics, but in my opinion it needs to be refuted vigorously. The fact that a few fragments of basalt are the oldest material in a particular hole has no connection with its crustal nature. If the basalt in DSDP were $218 \mathrm{Myr}$ old instead of the assessed 109 Myr old there could still be $1,000 \mathrm{~m}$ of little-disturbed strata below. In short, the age of the ocean basins is a problem as wide open now as it was when DSDP drilling began.

In the last analysis my observations are addressed not so much to Hammond et $a l$. in particular as to shipboard scientists in general. The scientists seem to go to sea convinced and/or indoctrinated that every piece of basalt is not only the bottom of the stratal sequence but also the bottom of the world. I have no proof to offer that their conviction and/or their indoctrination is incorrect. I submit only that if we are to be comparatively scientific about the nature of the ocean basins we had better drill some $20,000 \mathrm{~m}$ of basalts in suitably distributed DSDP holes. Only then could there be a geological dialogue of substance with respect to some of the matters indicated here.

M. KAMEN-KAYE

\section{Waterhouse Street, \\ Cambridge,}

Massachusetts 02138

I Hanmond, S. R., et al., Nuture, 255, 46 (1975). 2 Cox, A., and Dalrymple, G. B., J. geophys. Res., $72,2603(1967)$

3 MacDougall, D., Science, 171, 3977 (1971). 